\title{
Effectiveness of sensory processing strategies on activity level in inclusive preschool classrooms
}

\author{
This article was published in the following Dove Press journal: \\ Neuropsychiatric Disease and Treatment \\ 19 October 2012 \\ Number of times this article has been viewed
}

\author{
Chien-Lin $\operatorname{Lin}^{1,2}$ \\ Yu-Fan $\mathrm{Min}^{3}$ \\ Li-Wei Chou ${ }^{1,2, *}$ \\ Chin-Kai Lin ${ }^{4, *}$ \\ 'Department of Physical Medicine \\ and Rehabilitation, China Medical \\ University Hospital, Taichung, Taiwan; \\ ${ }^{2}$ School of Chinese Medicine, College \\ of Chinese Medicine, China Medical \\ University, Taichung, Taiwan; \\ ${ }^{3}$ Faith, Hope and Love, Center for \\ Children and Adults With Disabilities, \\ Taichung, Taiwan; ${ }^{4}$ Program of Early \\ Intervention, Department of Early \\ Childhood Education, National \\ Taichung University of Education, \\ Taichung, Taiwan \\ *These authors contributed equally to \\ this work
}

Background: The purpose of this study was to investigate the effectiveness of sensory processing strategies in improving the activity level of children with sensory integration dysfunction. Methods: The study used a matching-only pretest-posttest control group design, which requires random matching of sensory integration dysfunction to the corresponding intervention group $(\mathrm{n}=18)$ and control group $(\mathrm{n}=18)$. The intervention group comprised 3-6-year-old children who received an 8-week school-day intervention during implementation of the theme curriculum.

Results: The 8-week treatment significantly reduced the activity level and foot-swinging episodes in children with sensory integration dysfunction, and obtained a medium-effect size. However, the level of improvement in the control group did not show any statistically significant change.

Conclusion: Sensory processing strategies could improve activity levels in children with sensory integration dysfunction. However, this study was unable to exclude a developmental effect. The social validity results show that sensory processing strategies can be integrated into the theme curriculum and improve activity levels in children.

Keywords: activity level, preschool inclusive classroom, sensory integration dysfunction, sensory processing strategy

\section{Introduction}

Sensory integration therapy is frequently performed by occupational therapists and pediatric practitioners as a service in schools. In the United States, the proportion of children who typically develop sensory integration dysfunction is $5 \%-10 \% .{ }^{1,2}$ A study in Taiwan revealed that around $21 \%-28 \%$ of preschool children have sensory integration dysfunction. ${ }^{3}$

Under the least restrictive environmental provisions of the Special Education Act of Taiwan, related services initially implemented an itinerant program of school-based collaborative occupational therapy consultation in 1995. This multidisciplinary collaborative teaching model provides direct and indirect teaching services to kindergartens, and offers consultation services to parents and teachers. The teachers and occupational therapists form a professional team and develop individualized educational plans to meet the children's learning needs and to facilitate their adaptability. The indirect consultation service is most commonly provided because of the shortage of related service manpower, and limited attendance, space, and budgets in schools.

Preschool children with sensory integration dysfunction do not receive occupational therapy in hospitals. Sensory integration dysfunction, especially its attendant symptoms of sensory-seeking and overresponsivity, affects the performance of children in schools
Correspondence: Chin-Kai Lin

140 Min-Shen Road,

Taichung 40306, Taiwan

Tel +886 422183007

Fax +886 422183380

Email linchinkai97@gmail.com 
because it causes excessive movement ${ }^{4}$ (eg, shaking the feet, rocking the chair, rolling on the floor, wriggling the body, and manipulating things excessively). Sensory integration dysfunction also causes hyperactivity, ${ }^{5}$ an inability to sit still, ${ }^{1}$ an urge to disturb other students, responsiveness to irrelevant stimulation, ${ }^{6}$ inability to concentrate on relevant stimulation, ${ }^{7}$ and inability to participate in class work. Although the sensory processing problems in children who typically develop sensory integration dysfunction are milder than those of children with developmental disorders, these problems still affect their capacity to undertake schoolwork.

Children seek multiple types of sensory information, including vestibular, proprioceptive, tactile, auditory, and olfactory information. Therefore, occupational therapists need to evaluate the pattern of sensory-seeking. Sensory processing strategies based on child-directed and sensoryrich experiences should be provided for children. The sensory modalities provided must also match the preference of children.

A recent article in a pediatrics journal proposed that occupational therapists and other health professionals use a sensory processing approach when children have difficulty participating in everyday activities. However, the effects of sensory-based therapies should be monitored. ${ }^{8}$

According to the theory of sensory integration, deep pressure and vestibular and proprioceptive input can modulate the processing of sensory information in the reticular formation and limbic system, ${ }^{9}$ achieve the ideal level of alertness in the central nervous system, ${ }^{10,11}$ and reduce excessive actions and activity levels. Based on this theory, occupational therapists can provide activities that can be executed in the classroom. For example, the children may be required to sit on a ball chair or water cushion to enhance vestibular perception. They can also be asked to wear a weighted vest, carry a school bag with a water-filled bottle on their back, or sit on a T-stool during lessons to improve proprioception. The children may also be required to grasp or press clay to enhance tactile input and adjust the level of alertness in their central nervous system.

Previous studies of sensory processing strategies have focused on weighted vests, seat cushions, and ball chairs. A study of the effectiveness of a weighted vest found that it could increase goal-directed play in children with developmental disorder or delay. ${ }^{12,13}$ Wearing a weighted vest could also reduce nonengagement play, ${ }^{12,13}$ increase attention to tasking, decrease self-stimulatory behaviors, ${ }^{13,14}$ and improve on-task behavior during fine motor activities in the classroom. ${ }^{13,15}$ Sitting on a cushion can improve attention. ${ }^{6}$ Sitting on a ball chair can improve in-seat behavior and legible word productivity in children with attention deficithyperactivity disorder, ${ }^{16}$ and promote engagement and inseat behavior in children with autism spectrum disorder. ${ }^{17}$ Teachers also confirm that use of a ball demonstrates social validity. Bagatell et al propose that the characteristics of children with autism spectrum disorder should be considered in the provision of a ball chair, because the ball can increase the in-seat behavior of children, characterized by vestibularproprioceptive seeking, although it has a negative effect in children with poor postural stability. ${ }^{18}$ However, some studies have shown that using weighted or pressure vests has no significant effect. ${ }^{19-21}$

The sensory processing strategies suggested by occupational therapists have clearly benefited general education teachers. ${ }^{22}$ According to Hanft and Shepard, the sensory processing strategies used in inclusive classrooms are better than those used in biweekly hospital treatments, especially during in the preschool age group. ${ }^{23}$

Many studies of the effectiveness of sensory processing strategies were developed using a single-subject research design. These studies are limited to generalizations of clinical practice, while others focus on individual cases or other situations. Most of the earlier studies tested the use of a single sensory strategy, such as a weighted vest, ${ }^{12,14,15,20,21,24}$ ball chair, ${ }^{18}$ or seat cushion. ${ }^{6}$ Although these studies could discuss a single sensory strategy in depth, use of such a strategy is not sufficient to achieve the objective of educational plans at the individual level or to meet the needs of children in the classroom. In addition, although previous sensory processing strategies are valid, some studies have revealed their negative effects due to methodological weakness ${ }^{19}$ or to the use of only one sensory processing strategy. For example, subjects in some studies could not direct their head or eyes to the teacher, ${ }^{21}$ and instead disturbed other children participating in class activity. ${ }^{20}$ Individual differences in physiological responses and the unique features of sensory processing cause sensory demands to vary according to person and time..$^{25,26}$ Generally, sensory demands involve more than one sensory system $^{25}$ or strategy.

Therefore, this research considered internal and external validity in implementing the experimental design. In this study, we analyzed sensory processing problems in children and provided consultation for teachers in a classroom setting for 8 weeks. We also provided practical, graded tactile, proprioceptive, and vestibular input required by children with sensory integration dysfunction to influence their activity level. The viewpoint of teachers regarding the effect of sensory processing strategies was investigated as well. 
The findings of this study could guide occupational therapists in schools concerning the implementation of sensory processing strategies.

We tested two hypotheses derived from the research literature and from the clinical experience of sensory processing strategies for children aged 3-6 years with sensory integration dysfunction. These hypotheses were that the activity level is significantly reduced after use of sensory processing strategies and that improvement in activity level would be significantly greater in an intervention group than in a control group.

\section{Materials and methods Design}

This study used a matching-only pretest-posttest control group design with random assignment to a control or intervention group. The design aimed to determine the effectiveness of sensory processing strategies in improving activity level, energy expenditure, activity intensity, and feet-swinging episodes. The intervention group received a school-day intervention for 8 weeks, which involved sensory processing strategies for 1-2 hours a day 5 days a week. The control group did not receive any such intervention.

\section{Participants}

The study initially conducted a sensory processing function screening in four public or private kindergartens in three towns in central Taiwan. A total of 326 preschool children aged 3-6 years took the screening test. Only 38 children met the inclusion criteria. Because two students transferred to another school during the study period, the study participants were reduced to 36 children. The inclusion criteria considered children: who ranked in the 73rd percentile or higher on the Test of Sensory Integration Function, and on each of its three subtests related to the study (ie, sensory modulation, sensory seeking, and attention); who did not receive any sensory integration treatment during or before the study; and who could be matched to the intervention and control groups. Exclusion criteria were: developmental disorder, such as cerebral palsy, autism, or mental retardation; non-compliance with classroom rules for using the sensory device; lack of parental permission to participate in the study; and transfer to another school during the study period.

\section{Outcome measures}

The Test of Sensory Integration Function was developed in 2004 to identify sensory integration dysfunction. Its subtests are as follows: postural movement, bilateral integration sequencing, sensory discrimination, sensory modulation, sensory searching, attention and activity levels, and emotional behavior. ${ }^{27}$ Each item is scored on a five-point Likert scale. The range of possible raw scores on the total scale is 98-490, with higher scores indicating poorer performance. Answering the entire questionnaire takes teachers 20 minutes. A percentile rank of 73-84 indicates poor sensory integration function, 85-94 indicates borderline function, and $\geq 95$ indicates deficient function. ${ }^{28}$ This research tool has strong test-retest reliability $(0.87)$, and the seven subscales have acceptable construct validity. ${ }^{28}$ The Test of Sensory Integration Function was used to select candidates for this research, and to classify sensory problems into being vestibular, proprioceptive, or tactile in nature, or a combination of two or three of these.

The Actical ${ }^{\circledR}$ physical activity monitor (Mini Mitter Company, Bend, OR) was used to measure the dependent variable. This device uses an accelerometer to monitor the appearance and intensity of motion. Its omnidirectional sensor integrates the amplitude and frequency of motion in all directions, and produces an electrical current that varies in magnitude. An increase in intensity of motion causes an increase in voltage. The Actical device stores this information on movement in the form of activity counts. It uses four dependent variables, ie, activity level, energy expenditure, activity intensity, and feet-swinging episodes, to measure physical activity.

The sampling epoch, ie, the data collection unit, is one minute. The activity level is the average total number of activity counts within an epoch. The Actical device converts activity counts into energy units (calories). The energy expenditure equals activity level by weight, which indicates calorie consumption. Activity intensity can be categorized into four classes, as follows: a sedentary state, such as when sleeping and being still; light activity, such as playing a game console; moderate activity, such as walking, cleaning, aerobics, or ball tossing; and vigorous activity, such as treadmill exercise or jogging. The demarcation points of the four classes of activity intensity are $0.01,0.04$, and $1.00 \mathrm{kcal} / \mathrm{kg} / \mathrm{min}$, respectively. ${ }^{29}$ Step number refers to the number of feet-swinging episodes while walking and number of times the feet are wriggled during the measurement period. A monitor is constantly attached to the right ankle of the participant. The Actical device can accurately measure the level of indoor activity, energy expenditure, and frequency and intensity of activity. ${ }^{30}$

\section{Procedures}

Without any prior contact with potential participants, the researchers invited kindergartens from three towns in central 
Taiwan to participate in the study. Four kindergartens agreed to participate. The directors of the kindergartens assisted by sending letters of request for consent to parents. After written consent was received from the parents, the Test of Sensory Integration Function (ie, the screening test) was administered by the teachers to 326 children aged 3-6 years from the four kindergartens. During the preliminary examinations, the teachers did not know the groups to which the children would be assigned. Subjects who met the research criteria were randomly divided into two groups. Matched random sampling was used to assign participants who had relative sensory integration dysfunction based on the results of their Test of Sensory Integration Function assessment. This step ensured that each group had an equal number of participants. Before the intervention, the participants were monitored by the Actical device to collect data during the theme curriculum in the classroom. The researchers and occupational therapists explained the use, rules, functions, and possible adverse events associated with each sensory device to the 12 teachers allocated to the intervention group. The rules did not permit playing with the sensory device, damaging the device, or attacking other participants. For example, subjects were prohibited from throwing the ball to another person, piercing it, or bouncing it vigorously.

The study classified sensory processing into four types based on our sensory list. The first type is the vestibular sensory type, which is often applied when using a ball chair, a rocking horse, or a water cushion. The second is the proprioceptive sensory type, which is applied when using a weighted vest, a heavy schoolbag weighing $5 \%$ of the child's weight, a T-stool, or a sand ball. The third is the tactile type, which is applied when using a tactile wedge, clay, bar, ball, neck tactile ring, or a bean bag. The fourth is the mixed type. A ball chair and a T-stool were placed inside a carton box at knee height to avoid gliding and for stability. The teachers were instructed by the occupational therapists to provide the children with the relative sensory modalities during implementation of the recommended theme curriculum. For example, when a child had vestibular sensory problems, according to their result on the Test of Sensory Integration Function, vestibular sensory devices were provided, such as the ball chair, rocking horse, and water cushion.

The preschool teachers routinely implemented these sensorimotor activities from 9 am to $11 \mathrm{am}$. The teacher recorded the children's reactions daily on recording sheets. The researchers discussed the reactions and the sensory strategies used in the classroom with the teachers to generate references during the fortnightly adjustment of sensory devices from the sensory list of the same sensory type. The adjustment sensory input method consisted of a new sensory input provided in the relevant sensory system problem. After completing the intervention, the teachers answered the survey questionnaire about the effect of the sensory strategies. The items in the questionnaire were as follows:

- Do you agree that this sensory processing strategy could be integrated into teaching activities?

- What did you think the improvement in activity levels was for the children in your class?

- Did you want to continue the sensory processing strategy after the end of the intervention period?

- What was the most effective sensory device used by children in your class?

\section{Data analysis}

We used the Statistical Package for Social Sciences (SPSS) version 13.0 (IBM Corporation, Armonk, NY) to test for differences between the results of the pretest and posttest activity levels, energy expenditure, intensity of activity, and footswinging episodes measured. The paired $t$-test was used to test for differences in progress between the pretest and posttest in the two groups. The d value developed by Cohen ${ }^{31}$ was used to evaluate the effect size of the intervention. The criterion for statistical significance was set at 0.05 in this study.

\section{Results}

The mean age of the 36 subjects was $64.64 \pm 0.06$ (range 36-72) months. The intervention and control groups comprised 18 participants each. The intervention group comprised nine girls and nine boys, whose mean age was $66.33 \pm 7.84$ months. The control group comprised ten boys (55.56\%) and eight girls (44.44\%), whose mean age was $62.94 \pm 10.06$ months. The ratio of males to females and the ages of the intervention group and the control group were not significantly different.

The paired $t$-test was used to determine whether the pretests for the two groups were equivalent in design. The pretest did not reach statistical significance in either group in terms of activity level $(t[34]=0.34, P=0.73)$, energy expenditure $(t[34]=1.08, P=0.29)$, intensity of activity $(t[34]=0.68, P=0.5)$, or foot-swinging episodes $(t[34]=0.78, P=0.44)$.

The paired one-tailed $t$-test was used to determine if any significant improvement occurred after the posttest at 2 months. The intervention group showed a significant difference in terms of activity level $(t[17]=2.09, P=0.03)$ and feet-swinging episodes $(t[17]=2.26, P=0.02)$. The mean 
pretest activity level in the intervention group was 265.63 activity counts, while the mean posttest activity level was 163.03 activity counts (Table 1).

Therefore, each the activity level decreased by 102.6 activity counts per minute on average. The intervention effect size was $d=0.43$. The number of foot swings per second decreased by 3.78 . The intervention effect size was $d=0.52$. The effect was of medium size. However, the energy expenditure and activity level of the intervention group improved, but did not reach a statistically significant level. The four physical activity indices of the pretest and posttest in the control group did not reach statistical significance.

With regard to the matching group method, the paired $t$-test was used to compare differences in terms of activity level, energy expenditure, activity intensity, and footswinging episodes between the two groups. The change in these aspects was larger in the intervention group than in the control group (Table 2), although the difference did not reach statistical significance.

The effect of the questionnaire was completed within 1 week after the period of intervention. Ten teachers (83.3\%) agreed that the sensory processing strategy could be integrated into teaching activities. They also observed improvement in the children's activity levels. The teachers reported that the impressive improvements seen in participants using the sensory device in class included more focus in class, better emotional behavior, a longer attention span, sitting quietly for longer, less shaking of their feet and playing with small objects, and less chair rocking. Nine teachers (75\%) wanted to continue the sensory processing strategy after the intervention period. In the teachers' opinion, the most effective sensory devices were the clay and heavy school bag. The second most effective devices were the water cushion, ball chair, and tactile ball. The rocking horse was disruptive in class because it drew too much attention, causing the children to ignore the teacher. One teacher commented that when the children held the tactile ball, their activity level was reduced. However, the teacher was afraid that their attention would remain on the tactile ball instead of on the lesson. One teacher remarked that the sensory process strategy led to more time and attention being spent on whether the children followed the rules for its use, and she expressed a limited desire to use the strategy in class.

\section{Discussion}

The objective of this study was to determine how sensory processing strategies in the theme curriculum could reduce excessive activity levels in children with sensory integration dysfunction. We found that vestibular perception, proprioceptive perception, and tactile sensory processing strategies could reduce activity levels and foot-swinging episodes in children with sensory integration dysfunction. The activity level improved in the intervention group. However, the degree of improvement was insufficient to exclude a developmental effect. The lack of a statistically significant difference might reflect the inadequate curative period which, in this study, was only 8 school weeks. The treatment effect in this study and in previous studies did not reach statistical significance, mainly because of the short intervention period. For example, Reichow et al reported a treatment period for a weighted vest lasting 20 school days, ${ }^{21}$ with intervention using the same method lasting for only 2 weeks in $2009 .{ }^{20} \mathrm{~A}$ longer intervention period could show a significant treatment effect. Correspondingly, the ball chair intervention reported by Schilling et al lasted 12 weeks, ${ }^{16}$ the sensory processing strategy intervention reported by Case-Smith and Bryan lasted 10 weeks, ${ }^{12}$ and the intervention reported by Schaaf and Nightlinger lasted 10 months. ${ }^{32}$

Our study involved a limited number of subjects in the intervention group, raising the question of a type II error accounting for the lack of a significant difference in progress of the two groups. Another limitation of the study was the narrow geographic location of the sample. Therefore, we recommend that future studies increase the number of subjects in the intervention group.

Table I Effects of sensory processing strategies on activity level, energy expenditure, and activity intensity steps

\begin{tabular}{|c|c|c|c|c|c|c|c|c|}
\hline \multirow[t]{3}{*}{ Variable } & \multicolumn{4}{|c|}{ Treatment } & \multicolumn{4}{|c|}{ Control } \\
\hline & \multicolumn{2}{|c|}{ Pretest } & \multicolumn{2}{|c|}{ Posttest } & \multicolumn{2}{|c|}{ Pretest } & \multicolumn{2}{|c|}{ Posttest } \\
\hline & $M$ & SD & $M$ & SD & $M$ & SD & $M$ & SD \\
\hline $\mathrm{AL}$ & 265.63 & 239.10 & 163.03 & 131.98 & 239.49 & 217.10 & 157.74 & 103.13 \\
\hline EE & 0.03 & 0.05 & 0.02 & 0.03 & 0.02 & 0.01 & 0.02 & 0.01 \\
\hline $\mathrm{Al}$ & 1.82 & 0.37 & 1.68 & 0.40 & 1.73 & 0.42 & 1.64 & 0.33 \\
\hline Steps (n) & 11.23 & 7.33 & 7.45 & 6.07 & 9.44 & 6.53 & 7.36 & 5.02 \\
\hline
\end{tabular}

Note: Step number refers to the number of steps while walking and number of times wriggling the feet during the measurement period. Abbreviations: Al, activity intensity; AL, activity level; EE, energy expenditure; M, mean; SD, standard deviation. 
Table 2 Difference of posttest-pretest on dependent variables of two groups

\begin{tabular}{|c|c|c|c|c|c|c|}
\hline & \multicolumn{2}{|c|}{$\begin{array}{l}\text { Treatment } \\
\text { Difference posttest-pretest }\end{array}$} & \multicolumn{2}{|c|}{$\begin{array}{l}\text { Control } \\
\text { Difference posttest-pretest }\end{array}$} & \multirow[t]{2}{*}{ Paired $t$} & \multirow[t]{2}{*}{ P-value } \\
\hline & $M$ & SD & $M$ & SD & & \\
\hline $\mathrm{AL}$ & -102.60 & 207.84 & -81.75 & 221.03 & 0.29 & $>0.05$ \\
\hline EE & -3.78 & 7.08 & -2.09 & 7.14 & 0.40 & $>0.05$ \\
\hline $\mathrm{Al}$ & -0.01 & 0.05 & 0.00 & 0.01 & 0.40 & $>0.05$ \\
\hline Steps (n) & -0.14 & 0.35 & -0.09 & 0.44 & 0.72 & $>0.05$ \\
\hline
\end{tabular}

Note: Step number refers to the number of steps while walking and number of times wriggling the feet during the measurement period.

Abbreviations: Al, activity intensity; AL, activity level; EE, energy expenditure; M, mean; SD, standard deviation.

The study reported by Miller et al on the effectiveness of occupational therapy using a sensory integration approach adopted a one-group pretest and posttest design, and the result was the same as that for the intervention group in our study, indicating that the activity level of sensory-seeking can be reduced. ${ }^{33}$ The study focus on previous sensory processing strategies in attention deficit-hyperactivity disorder children has involved in-seat or on-task behavior. Pfeiffer et al used self-control and behavior regulations to measure on-task behavior. ${ }^{6}$ Schilling et $\mathrm{al}^{16}$ and Schilling and Schwartz ${ }^{17}$ measured in-seat behavior, while VandenBerg measured on-task seconds..$^{15}$ The current study is different because it measured activity levels. Therefore, it contributes to the knowledge of the effect of sensory processing in classroom practice.

Energy expenditure is equal to the activity level converted into calories by weight. Thus, it represents the energy expenditure of each person per minute. The value of the standard deviation for energy expenditure pretest and posttest in the intervention group was higher than that of the mean score. The individual energy expenditure difference in the intervention group was very high, while the standard deviation was large. The individual difference in the control group was smaller. The average calorie consumption per minute in the teaching activity of the classroom theme curriculum corresponded to the sedentary class of activity intensity. Activity intensity, measured by an ordinal scale, indicates the energy expenditure in the classroom activity. Thus, it is not sensitive enough to monitor the change of activity intensity between pretest and posttest.

In this study, the Actical physical activity monitor was attached to the right ankle of each study participant, using a belt in the proper orientation of the sensor to avoid attracting the attention of other children. The instrument was innovative and exciting for the children, and encouraged them to demonstrate it to other students. The psychological factor increased the number of foot swings. The pretest-posttest control group design of this study would be able to eliminate the influence of such a factor.
Our study screened children who complied with the criterion of being higher than the 73th percentile and identified 326 children, but only 36 subjects met the criteria for inclusion in this research. According to the test data, the Test of Sensory Integration Function score of $67 \%$ in the intervention group and $45 \%$ in the control group was at the 73rd to 84th percentile, indicating mild sensory integration dysfunction. The limited number of participants in the current study made classification according to dysfunction level impossible. Future studies should investigate the extent of the effect of intervention on sensory integration dysfunction.

\section{Conclusion}

Sensory processing strategies could improve activity levels and number of foot swings in children with sensory integration dysfunction, but could not exclude a developmental effect. Sensory processing multistrategies can be integrated into the theme curriculum.

\section{Disclosure}

The authors report no conflicts of interest in this work.

\section{References}

1. Ayres AJ. Sensory Integration and Praxis Tests. Los Angeles, CA: Western Psychological Services; 1989.

2. Ahn RR, Miller LJ, Milberger S, McIntosh DN. Prevalence of parents' perceptions of sensory processing disorders among kindergarten children. Am J Occup Ther. 2004;58:287-293.

3. Wu H-M. Sensory Integration Clinical Observation using Visual Surveillance-based Computerized Performance Assessment and its Validation. Taipei, Taiwan: Department of Educational Psychology and Counseling, National Taiwan Normal University; 2009.

4. Mangeot SD, Miller LJ, McIntosh DN, et al. Sensory modulation dysfunction in children with attention-deficit-hyperactivity disorder. Dev Med Child Neurol. 2001;43:399-406.

5. Parush S, Sohmer H, Steinberg A, Kaitz M. Somatosensory functioning in children with attention deficit hyperactivity disorder. Dev Med Child Neurol. 1997;39:464-468.

6. Pfeiffer B, Henry A, Miller S, Witherell ST. The effectiveness of Disc 'O' Sit cushions on attention to task in second-grade students with attention difficulties. Am J Occup Ther. 2008;62:274-281.

7. Miller LJ, Coll JR, Schoen SA. A randomized controlled pilot study of the effectiveness of occupational therapy for children with sensory modulation disorder. Am J Occup Ther. 2007;61:228-238.

8. Zimmer M, Desch L. Sensory integration therapies for children with developmental and behavioral disorders. Pediatrics. 2012;129: 1186-1189. 
9. Williams MS, Shellenberger S. How does your Engine run? A Leader's Guide to the Alert Program for Self-Regulation. Albuquerque, NM: Therapy Works; 1994.

10. Bundy AC, Lane SJ, Murray EA. Sensory Integration Theory and Practice. Philadelphia, PA: Davis Company; 2002.

11. Parham LD, Mailloux Z. Sensory Integration. In: Case-Smith J, editor. Occupational Therapy for Children. 4th ed. St Louis, MO: Mosby; 2001.

12. Case-Smith J, Bryan T. The effects of occupational therapy with sensory integration emphasis on preschool-age children with autism. Am J Occup Ther. 1999;53:489-497.

13. Olson LJ, Moulton HJ. Use of weighted vests in pediatric occupational therapy practice. Phys Occup Ther Pediatr. 2004;24:45-60.

14. Fertel-Daly D, Bedell G, Hinojosa J. Effects of a weighted vest on attention to task and self-stimulatory behaviors in preschoolers with pervasive developmental disorders. Am J Occup Ther. 2001;55:629-640.

15. VandenBerg NL. The use of a weighted vest to increase on-task behavior in children with attention difficulties. Am J Occup Ther. 2001;55: 621-628.

16. Schilling DL, Washington K, Billingsley FF, Deitz J. Classroom seating for children with attention deficit hyperactivity disorder: therapy balls versus chairs. Am J Occup Ther. 2003;57:534-541.

17. Schilling DL, Schwartz IS. Alternative seating for young children with autism spectrum disorder: effects on classroom behavior. JAutism Dev Disord. 2004;34:423-432.

18. Bagatell N, Mirigliani G, Patterson C, Reyes Y, Test L. Effectiveness of therapy ball chairs on classroom participation in children with autism spectrum disorders. Am J Occup Ther. 2010;64:895-903.

19. Stephenson J, Carter M. The use of weighted vests with children with autism spectrum disorders and other disabilities. J Autism Dev Disord. 2009;39:105-114.

20. Reichow B, Barton EE, Good L, Wolery M. Brief report: Effects of pressure vest usage on engagement and problem behaviors of a young child with developmental delays. J Autism Dev Disord. 2009;39: 1218-1221.

21. Reichow B, Barton EE, Sewell JN, Good L, Wolery M. Effects of weighted vests on the engagement of children with developmental delays and autism. Focus Autism Other Dev Disabl. 2010;25:3-11.
22. Mulligan S. Classroom strategies used by teachers of students with attention deficit hyperactivity disorder. Phys Occup Ther Pediatr. 2001;20:25-44.

23. Hanft B, Shepard J. Collaborating for Student Success: A Guide for School-based Occupational Therapy. Bethesda, MD: AOTA Press; 2008.

24. Kane A, Luiselli JK, Dearborn S, Young N. Wearing a weighted vest as intervention for children with autism/pervasive developmental disorder: behavioral assessment of stereotypy and attention to task. Scientific Review of Mental Health Practice. 2004/2005;3:19-24.

25. Dunn W. The sensations of everyday life: empirical, theoretical, and pragmatic considerations. Am J Occup Ther. 2001;55:608-620.

26. Zuckerman M. Behavioral Expressions and Biosocial Bases of Sensation Seeking. New York, NY: Cambridge University Press; 1994.

27. Lin CK. Test of Sensory Integration Function: User's Manual. Taipei, Taiwan: Psychological Corporation; 2004.

28. Lin CK. [The development of the test of sensory integration functions assessment scale]. Psychological Testing. 2010;57:403-432. Chinese.

29. Puyau MR, Adolph AL, Vohra FA, Zakeri I, Butte NF. Prediction of activity energy expenditure using accelerometers in children. Med Sci Sports Exerc. 2004;36:1625-1631.

30. Pfeiffer KA, McIver KL, Dowda M, Almeida MJ, Pate RR. Validation and calibration of the Actical accelerometer in preschool children. Med Sci Sports Exerc. 2006;38:152-157.

31. Cohen J. Quantitative methods in psychology: a power primer. Psychol Bull. 1992;112:155.

32. Schaaf RC, Nightlinger KM. Occupational therapy using a sensory integrative approach: a case study of effectiveness. Am J Occup Ther. 2007;61:239-246.

33. Miller LJ, Schoen SA, James K, Schaaf RC. Lessons learned: a pilot study on occupational therapy effectiveness for children with sensory modulation disorder. Am J Occup Ther. 2007;61:161-169.
Neuropsychiatric Disease and Treatment

\section{Publish your work in this journal}

Neuropsychiatric Disease and Treatment is an international, peerreviewed journal of clinical therapeutics and pharmacology focusing on concise rapid reporting of clinical or pre-clinical studies on a range of neuropsychiatric and neurological disorders. This journal is indexed on PubMed Central, the 'PsycINFO' database and CAS.

\section{Dovepress}

The manuscript management system is completely online and includes a very quick and fair peer-review system, which is all easy to use. Visit http://www.dovepress.com/testimonials.php to read real quotes from published authors. 